\title{
Utilization of LCP-Tacrolimus (Envarsus XR) in Simultaneous Pancreas and Kidney
} Transplant Recipients

\author{
Julia Torabi, BS, ${ }^{1,2}$ Alesa Campbell, PharmD, ${ }^{2}$ Maria Ajaimy, MD, ${ }^{1,2}$ Juan P. Rocca, MD, ${ }^{1,2}$ \\ Jay A. Graham, MD, MBA ${ }^{1,2}$ \\ ${ }^{1}$ Albert Einstein College of Medicine, Bronx, NY ${ }^{2}$ Montefiore-Einstein Center for Transplantation, Montefiore Medical Center, Bronx, NY
}

\section{TO THE EDITOR}

A higher incidence of rejection is seen in pancreas transplant recipients compared to those who receive kidney transplant alone. ${ }^{1}$ Niederhaus and colleagues found that $21 \%$ of pancreas transplant recipients either had acute cellular or antibody-mediated rejection. ${ }^{2}$ Notably, a marked graft failure rate is associated with chronic rejection. ${ }^{3}$ Efforts to counter this process principally involve lymphocyte-depleting induction agents, along with calcineurin inhibitor (CNI), antimetabolite, and corticosteroid maintenance regimens.

While immediate-release tacrolimus (IR-TAC), dosed twice per day, is routinely used for maintenance therapy, here we present our use of LCP-tacrolimus (LCPT; Envarsus XR) in patients who have undergone a simultaneous pancreas and kidney (SPK) transplant. LCPT is a novel formulation of TAC that results in an extended release of the drug throughout the gastrointestinal tract by incorporating the fairly water-insoluble drug molecule into a liquid vehicle that is sprayed onto an inert carrier. The liquid vehicle solidifies upon deposition onto the carrier, capturing the active TAC molecule in a solid dispersion. Compression of the drugcontaining liquid vehicle into tablets accounts for the improved absorption and bioavailability of LCPT and lower peak blood concentrations $\left(\mathrm{C}_{\max }\right)$, leading to fewer neurotoxic adverse effects. A randomized, double-blind, phase III trial in kidney transplant recipients analyzed the efficacy of LCPT vs IR-TAC, with the former requiring lower doses to achieve the trough level. ${ }^{4}$ Studies in kidney transplant recipients have demonstrated decreased $\mathrm{C}_{\max }$ and up to a $30 \%$ dose reduction with LCPT utilization. ${ }^{5,6}$ The STRATO (Switching STudy of Kidney TRansplant PAtients with Tremor to LCP-TacrO) trial underscored the benefits of this reduced dosing while examining the improvement in hand tremor with LCPT usage. ${ }^{7}$

Given these advantages, we opted to use LCPT in our SPK recipients. The increased immunogenicity of the pancreas allograft typically mandates trough levels of at least 8-10 ng/mL. LCPT was introduced with the desire to mitigate the $\mathrm{C}_{\max }$ necessary to achieve these levels. Moreover, the once-daily formulation of LCPT represents a solution for our subset of patients with type 1 diabetes who are generally younger than most transplant patients and for whom adherence may be a challenge.

\section{STUDY DESIGN AND RESULTS}

All pancreatic allografts were implanted in recipients utilizing systemic venous and enteric drainage. The pancreas was positioned in the right lower quadrant and the kidney was placed on the left. Recipients underwent induction with rabbit antithymocyte globulin (6 mg/kg cumulative dose), along with methylprednisolone taper per institution protocol. Our practice is to manage all pancreas transplant patients with nasogastric decompression. As LCPT cannot be administered sublingually or via a nasogastric tube, all patients were started on IR-TAC prior to conversion to LCPT. The 8 patients on LCPT maintenance were converted from IR-TAC on postoperative day 2-3 following removal of the nasogastric tube. The Table shows patient demographic information and outcomes, as well as donor ages. Maintenance immunosuppression consisted of IR-TAC $(n=20)$ or LCPT $(n=8)$ with target troughs of $10-12 \mathrm{ng} / \mathrm{mL}$, mycophenolate mofetil or mycophenolate sodium, and prednisone.

Endpoints assessed were the TAC coefficient of variability (CV) for outpatient troughs and biopsy-proven acute rejection (BPAR). A higher TAC CV has been shown to correlate with chronic kidney rejection and medication nonadherence patterns. ${ }^{8,9}$ Donor characteristics of age and cause of death were collected from DonorNet.

Five BPAR episodes occurred in the IR-TAC cohort vs none in the LCPT group. One patient in the LCPT group died at home under unknown circumstances; no deaths or graft losses were noted in the IR-TAC group. No difference was noted in the tacrolimus $\mathrm{CV}$ between the IR-TAC $(n=20)$ and LCPT $(n=7)$ groups at 1 month (32.2 vs $30.9, P=0.835)$ or between the IR-TAC $(n=20)$ and LCPT $(\mathrm{n}=5)$ groups at 3 months posttransplant (32.6 vs 32.9 , $P=0.952)$.

\section{DISCUSSION}

Information about LCPT and pancreas transplantation is limited. ${ }^{10}$ As such, this early, single-center experience is an important contribution to the literature. While the number of subjects does not allow for definitive conclusions, this observational study does provide an insight into LCPT usage in SPK recipients. In particular, 5 BPAR episodes occurred in the IR-TAC cohort despite no difference in the CV compared to the LCPT group. This curious finding deserves further 
Torabi, J

Table. Patient and Donor Demographic Information and Outcomes by Treatment Group

\begin{tabular}{|c|c|c|c|c|c|c|}
\hline Treatment Group & $\begin{array}{l}\text { Recipient } \\
\text { Age }\end{array}$ & $\begin{array}{l}\text { Recipient } \\
\text { Blood Type }\end{array}$ & $\begin{array}{l}\text { Recipient } \\
\text { Sex }\end{array}$ & $\begin{array}{l}\text { Donor } \\
\text { Age }\end{array}$ & Complications & Rejection \\
\hline \multirow{20}{*}{$\begin{array}{l}\text { Immediate-release } \\
\text { tacrolimus }\end{array}$} & 33 & $\mathrm{O}$ & $\mathrm{F}$ & 23 & & \\
\hline & 27 & $A$ & M & 19 & & \\
\hline & 32 & $\mathrm{O}$ & $\mathrm{F}$ & 25 & Gastrointestinal bleeding & \\
\hline & 32 & B & M & 13 & & \\
\hline & 51 & $\mathrm{O}$ & M & 20 & & \\
\hline & 40 & $\mathrm{O}$ & $\mathrm{F}$ & 14 & & \\
\hline & 41 & $\mathrm{O}$ & M & 19 & & \\
\hline & 31 & $\mathrm{O}$ & M & 24 & & BPAR \\
\hline & 34 & B & $\mathrm{F}$ & 20 & $\begin{array}{l}\text { Nonocclusive superficial } \\
\text { venous thrombosis }\end{array}$ & \\
\hline & 21 & B & M & 20 & & BPAR \\
\hline & 34 & $\mathrm{O}$ & M & 37 & & BPAR \\
\hline & 33 & $A B$ & M & 29 & & \\
\hline & 33 & $\mathrm{O}$ & M & 25 & & BPAR \\
\hline & 40 & $\mathrm{O}$ & $\mathrm{F}$ & 19 & & \\
\hline & 45 & $\mathrm{O}$ & $\mathrm{F}$ & 21 & & \\
\hline & 35 & $\mathrm{O}$ & M & 26 & & \\
\hline & 31 & A & $\mathrm{F}$ & 30 & $\begin{array}{l}\text { Nonocclusive superficial } \\
\text { venous thrombosis }\end{array}$ & BPAR \\
\hline & 52 & B & $\mathrm{F}$ & 33 & Wound infection & \\
\hline & 54 & $\mathrm{O}$ & M & 26 & Hyperkalemia & \\
\hline & 42 & $\mathrm{O}$ & $\mathrm{F}$ & 29 & & \\
\hline \multirow[t]{8}{*}{ LCP-tacrolimus } & 28 & $A B$ & M & 22 & $\begin{array}{l}\text { Graft pancreatitis, renal } \\
\text { allograft torsion }\end{array}$ & \\
\hline & 44 & $\mathrm{O}$ & M & 20 & & \\
\hline & 43 & $\mathrm{O}$ & M & 20 & & \\
\hline & 46 & $A$ & $\mathrm{~F}$ & 28 & Wound infection, neutropenia & \\
\hline & 32 & B & $\mathrm{F}$ & 33 & Died & \\
\hline & 31 & $\mathrm{O}$ & M & 27 & & \\
\hline & 34 & $\mathrm{O}$ & $\mathrm{F}$ & 19 & & \\
\hline & 49 & A & M & 17 & & \\
\hline
\end{tabular}

BPAR, biopsy-proven acute rejection.

study; it is likely multifactorial and would benefit from a larger cohort powered to detect a difference. However, adherence patterns may play a role as LCPT allows for a 15-hour window to take this medication and still maintain a steady state blood concentration.

LCPT represents a beneficial option for the future of CNI-based immunosuppression for pancreas transplant recipients because of several advantages. The once-daily formulation may play an important role in mitigating obstacles to medication adherence. Given that SPK transplants maintain the longest half-life (16.7 years) compared to other solid organ transplants, reduction of $\mathrm{C}_{\max }$ may abrogate the cumulative effects of $\mathrm{CNI}$ neurotoxicity and islet cell dysfunction. Further efforts should be directed to understand the potential benefits afforded by LCPT in pancreas transplantation.

\section{ACKNOWLEDGMENTS}

Dr Jay Graham is the chief executive officer/founder of Transplant Hero LLC.

\section{REFERENCES}

1. Israni AK, Skeans MA, Gustafson SK, et al. OPTN/SRTR 2012 Annual Data Report: pancreas. Am J Transplant. 2014 Jan;14 Suppl 1:45-68. doi: 10.1111/ajt.12580.

2. Niederhaus SV, Leverson GE, Lorentzen DF, et al. Acute cellular and antibody-mediated rejection of the pancreas allograft: incidence, risk factors and outcomes. Am J Transplant. 2013 Nov;13(11):2945-2955. doi: 10.1111/ajt.12443.

3. Dong M, Parsaik AK, Kremers W, et al. Acute pancreas allograft rejection is associated with increased risk of graft failure in pancreas transplantation. Am J Transplant. 2013 Apr;13(4):10191025. doi: 10.1111/ajt.12167. 
4. Budde K, Bunnapradist S, Grinyo JM, et al. Novel once-daily extended-release tacrolimus (LCPT) versus twice-daily tacrolimus in de novo kidney transplants: one-year results of Phase III, double-blind, randomized trial. Am J Transplant. 2014 Dec;14(12):2796-2806. doi: 10.1111/ajt.12955.

5. Garnock-Jones KP. Tacrolimus prolonged release (Envarsus ${ }^{\circledR}$ ): a review of its use in kidney and liver transplant recipients. Drugs. 2015 Feb;75(3):309-320. doi: 10.1007/s40265-015-0349-2.

6. Staatz CE, Tett SE. Clinical pharmacokinetics of once-daily tacrolimus in solid-organ transplant patients. Clin Pharmacokinet. 2015 Oct;54(10):993-1025. doi: 10.1007/s40262015-0282-2.

7. Langone A, Steinberg SM, Gedaly R, et al; STRATO Investigators. Switching STudy of Kidney TRansplant PAtients with Tremor to LCP-TacrO (STRATO): an open-label, multicenter, prospective phase 3b study. Clin Transplant. 2015 Sep;29(9):796-805. doi: 10.1111/ctr.12581.
8. Vanhove T, Vermeulen T, Annaert P, Lerut E, Kuypers DRJ. High intrapatient variability of tacrolimus concentrations predicts accelerated progression of chronic histologic lesions in renal recipients. Am J Transplant. 2016 Oct;16(10):2954-2963. doi: 10.1111/ajt.13803.

9. Torabi J, Choinski K, Courson A, Zanetti-Yabur A, Rocca JP, Graham JA. Letter to the editor: mobile technology can improve adherence and lessen tacrolimus variability in patients receiving kidney transplants. Ochsner J. 2017 Fall;17(3):218-219.

10. Kerstenetzky L, Descourouez JL, Jorgenson MR, et al. A singlecenter experience with tacrolimus LCP (Envarsus XR) in pancreas transplant recipients. Ann Pharmacother. 2018 Apr;52 (4):392-396. doi: 10.1177/1060028017749076. 